for them to monitor whether any effective change had occurred. Only $17 \%$ of these schemes used information from routine data collection systems, supporting the comment by Ms Mugford and colleagues that the link between routine systems and clinical research and audit is tenuous. This survey was carried out at a time when interest in medical audit had just been awakened, and $37 \%$ of schemes were less than one year old; the situation may now be improved.

Evidence from countries such as Canada, ' where audit has been practised for far longer, suggests that problems with completing the audit loop are not unique. Though it is not clear how to alter clinical behaviour most effectively, it is essential that at least the basic principles of audit, such as documenting and monitoring progress, are established if the current input of resources is to be used to any effect.

JENNIFER HOLLOWELL PETER LITTLEJOHNS

Department of Public Health Scierices,

St George's Hospital Medical School,

London SW17 0RE

Department of Epidemiology

and Public Health,

University College and Middlesex Hospital Medical School,

London WC1E 6EA

1 Mugford M, Banfield P, O'Hanlon M. Effects of feedback of information on clinical practice: a review. BMF 1991;303: 398-402. (17 August.)

2 Easterbrook PJ, Berlin JA, Gopalan R, Matthews DR. Publication bias in clinical research. Lancet 1991;337:867-72.

3 Hollowell J, Ben-Shlomo Y. South West Thames regional survey of medical audit: report to the $S W$ Thames regional working party on medical audit. London: South West Thames Regional Health Authority, 1990.

4 Secretaries of State for Health in England, Wales, Norther Ireland, and Scotland. Working for patients, working paper 6 . Medical audit. London: HMSO, 1989

Parfrey PS, Gillespie M, McManamon PJ, Fisher R. Audit of the medical audit committee. Can Med Assoc F 1986;135:205-8.

\section{What now for IPPNW?}

SIR,-“One of the most successful medical organisations ever . . . over 200000 million [sic] doctors . . . the clarity, focus, and importance of its mission . . . too special and creative an organisation to be allowed to wither." Pr Richard Smith seems to have been carried away by his enthusiasm for International Physicians for the Prevention of Nuclear War (IPPNW)

IPPNW was indeed awarded the Nobel peace prize in 1985. But Dr Smith omitted to mention that this caused an outcry. The British and other Western governments protested, ${ }^{2}$ and the award was described as "the greatest blunder the Nobe Committee ever made." ${ }^{3}$ And no wonder. There is considerable evidence that IPPNW is a Soviet front organisation with aims that closely follow Soviet foreign policy, amounting in effect to cal for unilateral disarmament by the West. ${ }^{+} \mathrm{Dr}$ Yevgeny Chazov is a member of the Central Committee of the Communist Party of the Sovie Union and a deputy minister of health. It is clear that he founded, and serves in, IPPNW with the Kremlin's approval, and his views toe the official line. Dr Chazov is also head of the fourth division of the Ministry of Health, which has special responsibility for liaising with the KGB. ${ }^{5}$ As such he must bear some responsibility at least for committing Soviet dissidents to psychiatric prisons. In addition he was a signatory, with other members of the Soviet Union's Academy of Medical Sciences, of a shameful letter published in Izvestia on 26 September 1973 attacking Andrei Sakharov. Furthermore, IPPNW is associated with the notorious Dr Marat Vartanian, the chief defender of Soviet political psychiatric practices, ${ }^{56}$ who made a lecture tour in the United States in 1985 as part of a Soviet IPPNW delegation."

To claim that IPPNW "played an important part in dramatically reducing the chance of nuclear war" is absurd. The reduction in the risk of nuclear war has come about through the strength of the West and the collapse of Communism.

GABRIEL SYMONDS

Tokyo Medical and Surgical Clinic,

Minato-Ku

Japan

1 Smith R. What now for IPPNW? BMJ 1991;303:145-6. (20 July.

Prick 1985 Dec 11

Hawkes N. War of words on peace prize. Observer $1985 \mathrm{Dec} 3$.

4 Rosenblatt J. Soviet propaganda and the physicians' peace movement. Toronto: Mackenzie Institute, 1988 (Occasional paper

Wynn A, Reddaway P. What sort of peace do these men want Times 1985 Dec 3 .

6 Bloch S, Reddaway P. Soviet psychiatric abuse. London: Victor Gollancz, 1984.

\section{Drug Points}

\section{Anosmia due to nasal administration of} corticosteroid

Messrs H B Whittet, C Shinkwin, and A P FREELAND (Department of Otolaryngology, Radcliffe Infirmary, Oxford OX2 6HE) write: We report two cases of anosmia after the use of nasal corticosteroid preparations.

A 35 year old man with no history of olfactory disturbance presented with symptoms of vasomotor rhinitis. He had been using beclomethasone and betamethasone preparations with minimal benefit. He was prescribed a course of nasal drops containing betamethasone and neomycin sulphate (Betnesol-N) to be taken in the head down position. He stopped them, however, because he developed a violent burning sensation followed by complete anosmia. Examination showed erythematous changes in the nasal mucosa and olfactory cleft and a vesicular eruption at the nasal vestibule. $\mathrm{He}$ had regained partial olfactory function six months later.

A 42 year old woman was prescribed Betnesol-N nasal drops but experienced a violent burning sensation followed by complete anosmia. Examination showed generalised erythematous changes in the nasal mucosa extending superiorly towards the olfactory cleft. The anosmia showed no sign of resolving one year later.

Local side effects of simple betamethasone nasal drops are mild and include mucosal dryness, stinging, sneezing, and bleeding. ${ }^{12}$ The preservative used in these preparations is a quaternary ammonium compound which has been implicated in nasal allergic reactions. ${ }^{3}$ Betamethasone combined with neomycin sulphate is marketed as an "anti-infective" nasal preparation, although there is no evidence that these preparations have any therapeutic value. ${ }^{2}$ The preservative is thiomersal, a sodium salt of mercury, which is present in different concentrations. ${ }^{+}$It has similar adverse effects to mercury - hypersensitivity reactions with erythema and a papular or vesicular eruption - and causes allergic conjunctivitis. ${ }^{3}$

The olfactory mucosa occupies an exposed position in the nasal cavity and is therefore vulnerable to superficial irritants. Both of these patients showed acute reactions to these preparations followed by anosmia. The route of administration may have introduced the drug directly on to the olfactory mucosa. The reaction was probably due to the thiomersal, although a toxic effect of neomycin on the olfactory mucosa, similar to its ototoxic effects, cannot be discounted. Repeated use of local nasal preparations containing vasoconstrictors or neomycin has been implicated in olfactory dysfunction. ${ }^{5}$ The Committee on Safety of Medicines and the manufacturers have received reports of anosmia associated with use of beta- methasone alone, suggesting that the drug itself could be to blame. The clinical features in these cases, however, suggest that irritation was the cause.

Olfactory loss associated with anti-infective preparations of betamethasone is rare but has potential medicolegal implications. We believe this justifies caution in prescribing such products for common nasal conditions for which safer alternatives exist.

We thank Mrs E Sadler, pharmacist at the Radcliffe Infirmary, for her help in the preparation of this report.

Mackay I. Rhinitis: mechanisms and management. London: Royal Society of Medicine Services, 1989:183-96.

2 BMA and Royal Pharmaceutical Society of Great Britain. British national formulary. Number 20. London: BMA and Pharmaceutical Press, 1990:354.

3 Reynolds JEF, ed. Martindale: the extra pharmacopoeia. 29 th ed. London: Pharmaceutical Press, 1989:970.

4 Association of the British Pharmaceutical Industry. ABPI data sheet compendium 1989-90. London: Datapharm Publications, 1989:952-70.

5 Rebattu JP, Lafon $\mathrm{H}$, Cajgfinger $\mathrm{H}$. La pathologie iatrogène en otorhinolaryngologie. Lyon Medical 1972;118:787-91.

\section{Carbamazepine and spina bifida}

Drs PIPPA OAKEShotT (Department of General Practice, St George's Hospital Medical School, London SW17 0RE) and G M HuNT (Department of Urology, Addenbrooke's Hospital, Cambridge CB2 2QQ) write: Rosa has calculated that exposure to carbamazepine in utero, without concurrent exposure to valproic acid, carries a risk of spina bifida of $1 \% .^{1}$.We report the case of a woman who was taking only carbamazepine who gave birth to a baby with closed spina bifida.

A 27 year old woman gave birth at 36 weeks' gestation to a $3400 \mathrm{~g}$ live female infant with a lumbosacral myelomeningocele. The lesion was covered with skin, and there was no sensory loss. The mother had been diagnosed as suffering from epilepsy when she was 17 and had started taking carbamazepine. She had stopped treatment during her previous pregnancy, which had been normal. Throughout the current pregnancy, however, she had taken carbamazepine $600 \mathrm{mg}$ daily. She was not taking any other drugs. Ultrasound examinations at 13 and 16 weeks' gestation were reported as normal. She did not attend for amniocentesis.

The Committee on Safety of Medicines has received four further reports of spina bifida in babies whose mothers had taken carbamazepine. Two of the mothers were taking only carbamazepine but the other two were also taking sodium valproate. At present neither the datasheet for carbamazepine nor the British National Formulary mentions the risk of spina bifida. As with sodium valproate, teenage girls and women taking carbamazepine should be warned about the risk of spina bifida, offered preconceptional counselling, and advised about the need for specialist screening should they become pregnant. ${ }^{23}$

1 Rosa FW. Spina bifida in infants of women treated with carbamazepine during pregnancy. $N$ Engl f Med 1991;324: 6747.

2 Saunders $M$. Epilepsy in women of childbearing age. $B M \gamma$ 1989;299:581.

3 Sodium valproate and spina bifida. Drug Ther Bull 1990;28 $59-60$

\section{Correction}

\section{DMPA and bone density}

An editorial error occurred in this letter by $\mathrm{Mr} \mathrm{A}$ Kubba (24 August, p 467). The final paragraph should have read, "The conclusion ... should be addressed in a controlled prospective trial, preferably encompassing oestrogen free contraceptives which cause amenorrhoea." 